\title{
¿De acuerdo con el modelo?
}

Sección dirigida a sistematizar reflexiones sobre los principios, componentes y orientaciones educativas del Modelo Educativo de la UAA.

Esta primera edición ofrece al profesor una guía,

Norma Isabel Medina Mayagoitia con la intención de que los profesores autoevaluen su práctica docente de acuerdo con los planteamientos del Modelo Educativo Institucional.

\section{Aspectos A VALORAR}

1. La educación debe estar centrada en el estudiante y su aprendizaje.

2. La educación debe dirigirse a la formación profesional, intelectual, actitudinal, valoral, física, cultural y social del estudiante.

3. Estoy comprometido con la institución y sus metas educativas.

4. Tengo una actitud favorable hacia los procesos de enseñanza y aprendizaje.

5. Como profesor, promuevo constantemente que los estudiantes sean críticos y reflexivos.

6. Invito a los estudiantes a ser responsables y autónomos en su aprendizaje.

7. Busco actividades que estimulen el desarrollo de las capacidades de mis estudiantes.

8. Fomento la participación y el trabajo colaborativo entre los estudiantes.

9. Siempre tengo altas expectativas en mis estudiantes.

10. Identifico necesidades diferenciadas en los estudiantes.

11. Ofrezco apoyo individualizado a los estudiantes que lo requieran.

12. Cuento con la formación pedagógica necesaria para el ejercicio docente. 
13. Domino los contenidos de todas las asignaturas que imparto.

14. Retroalimento oportunamente el trabajo de los estudiantes.

15. Centro el proceso educativo en el aprendizaje de los estudiantes.

16. Planeo de manera sistemática el trabajo docente.

17. Utilizo metodologías que favorezcan el aprendizaje de los estudiantes.

18. Me considero un facilitador del aprendizaje.

19. Busco constantemente mi actualización como docente.

20. El aprendizaje se construye en la interacción entre estudiantes, profesor y contenidos.

21. Encamino el aprendizaje a la reflexión y solución de la problemática social.

22. Muestro apertura a metodologías no convencionales como la semipresencial, a distancia y en línea.

23. Realizo evaluaciones que corresponden a los contenidos que enseño.

24. Involucro a los alumnos en la evaluación, introduciendo actividades de autoevaluación y coevaluación.

25. Reoriento el proceso de enseñanza a partir de la evaluación del aprendizaje de los estudiantes.

Los anteriores aspectos valorados, provienen de los planteamientos y orientaciones del Modelo Educativo Institucional (MEI), por lo tanto, si seleccionó la primera columna para todos o la mayoría de los enunciados, usted es un profesor que probablemente conoce y definitivamente aplica este modelo de nuestra Universidad. Para quienes respondieron gran parte de los enunciados en las columnas dos y tres, los invitamos a familiarizarse con el MEI.

Este modelo, aprobado por el H. Consejo Universitario en 2006, se basa en la historia, vocación, misión, visión y fines de la Universidad Autónoma de Aguascalientes, de ahí que, como herramienta conceptual y operativa, establece un sólido compromiso con la formación integral y humanista de los estudiantes y exhorta a la comunidad universitaria a seguir sus principios y orientaciones para encaminarse a la calidad y a la mejora continua. Consulte el Modelo Educativo Institucional en la página de internet http://www.uaa.mx/pdf/modeloeducativo.pdf

Fuente completa:

Universidad (2007) Modelo Educativo Institucional. En correo universitario. Sexta época. Núm. 16. Publicado 15 de Marzo 2007. México: UAA. 